\title{
REVIEW
}

\section{Alterations of coronary blood flow and myocardial perfusion in hypercholesterolaemia}

\author{
Volker Schächinger, Andreas M Zeiher
}

\footnotetext{
J W Goethe University Frankfurt,

Department of

Internal Medicine IV

Division of Cardiology,

Frankfurt/Main,

Germany

V Schächinger

A M Zeiher

Correspondence to: Dr V Schächinger, Department of Internal Medicine IV, Division of Cardiology, J W Goethe Cardiology, J W Goethe University Frankfurt, Theodor-Stern-Kai 7, M-60590 Frankfurt

Accepted for publication 29 May 1996
}

Injury or dysfunction of endothelial cells is an important factor in atherogenesis. Impaired endothelium-dependent relaxation in atherosclerotic arteries has been reported in laboratory animals and humans. ${ }^{1}$ Recent evidence indicates that endothelial dysfunction is an early event, which may even precede the development of coronary atherosclerosis. ${ }^{2}$

Hypercholesterolaemia is an important cause of coronary artery disease in humans, and raised plasma concentrations of low density lipoproteins (LDL) are associated with accelerated atherogenesis. ${ }^{3}$ Moreover, hypercholesterolaemia impairs endothelial vasodilator function at a time when no abnormal structural alterations of the arterial wall are present, as assessed by light and electron microscopy in animals fed a high-cholesterol $\operatorname{diet}^{4}$ or as seen in the human forearm circulation. ${ }^{5}$

The endothelium plays a critical role in the control of vasomotor tone by synthesising and metabolising vasoactive substances including an endothelium-derived hyperpolarising factor, ${ }^{6}$ prostacyclin, ${ }^{7}$ and, most importantly, endothelium derived relaxing factor (EDRF), which is nitric oxide $(\mathrm{NO})^{8}$ or a related compound. ${ }^{9}$ A variety of agonists or physical stimuli including muscarinic receptors activated by acetylcholine induce endothelial cells to release NO into the subendothelial space. NO, derived from L-arginine, is thereby formed by the constitutively expressed NOsynthase of the endothelial cell. Subsequently, NO activates smooth muscle soluble guanylate cyclase to increase cyclic guanosine monophosphate concentrations thus leading to smooth muscle relaxation. ${ }^{7}$ Endothelium derived relaxing factor/NO is continuously synthesised and released under basal conditions in the arterial vascular beds of the coronary and peripheral circulations. ${ }^{10} \mathrm{~A}$ very important mechanism underlying NO/EDRF release in response to stimuli such as exercise is the shear stress exerted by the flowing blood upon the endothelial cell layer. ${ }^{11}$ The endothelial cell acts as a mechanotransducer perceiving local blood flow and converting increased shear stress into vessel wall relaxation, thereby optimising tissue perfusion according to metabolic needs. ${ }^{10}$

\section{Vascular biology in hypercholesterolaemia}

As the first step of fatty streak formation, apoB-containing lipoproteins (VLDL, LDL, chylomicron remnants) are entrapped in the subendothelial space where they undergo an oxidative modification. ${ }^{12}$ Mild oxidation results in minimally oxidised LDL (MMLDL) which can induce factors that cause monocyte chemotaxis, adhesion, and differentiation. This results in binding of monocytes to the endothelial cells, their migration into the subintimal space, and their differentiation to macrophages. ${ }^{12}$ The macrophages release reactive oxygen species and active aldehydes, leading to modification of MM-LDL into highly oxidised LDL, which further enhances recruitment of mononuclear cells into the vessel wall. Hypercholesterolaemia thus imposes a significant oxidative stress upon the vessel wall.

Hypercholesterolaemia impaired endothelial vasodilator function in large conduit vessels as well as in resistance vessels in experimental studies ${ }^{4}$ and in humans. ${ }^{1314} \mathrm{~A}$ study that found increased NO-synthase activity in the aortas of cholesterol-fed rabbits but reduced bioactivity of $\mathrm{NO}^{15}$ argues against reduced production of $\mathrm{NO}$ or alterations in NO-synthase, but accords with enhanced destruction of NO as the cause of defective endothelium-dependent vascular relaxation. Enhanced destruction of NO in hypercholesterolaemia seems to be related to increased production of free radicals, especially superoxide anions. ${ }^{16}$ In hypercholesterolaemia scavenging of superoxide anions by superoxide dismutase ameliorates endothelial vasodilator dysfunction in large vessels as well as in the microcirculation. ${ }^{17}$ Experimental studies indicate that reduced NO availability may act synergistically with oxidative stress to increase the production of the potent monocyte chemoattractant MCP-1. ${ }^{18}$ This would result in the adherence of leucocytes. High density lipoprotein (HDL) ameliorates endothelial dysfunction and has protective effects against a variety of unfavourable LDL actions. Thus, HDL reduces the effect of $\mathrm{LDL}$-induced oxidative stress by inhibiting the oxidation process of LDL, ${ }^{19}$ abolishing MCP-1 synthesis, ${ }^{20}$ and augmenting prostacyclin synthesis. ${ }^{21}$

In addition to impairing endothelial vasodilator function by oxidative stress, hyper- 
cholesterolaemia may interfere with receptoroperated signal transduction mechanisms linked to the formation of EDRF. Specifically, lysophosphatidylcholine, associated with the oxidised LDL molecule, may impair pertussis toxin-sensitive $G_{i}$ protein-dependent pathway which is used by, for example, serotonin and acetylcholine. ${ }^{22}$ In addition, oxidised LDL may decrease the receptor-mediated availability of L-arginine. ${ }^{23}$

\section{Endothelial modulation of coronary blood flow in humans \\ EPICARDIAL ARTERIES}

In the absence of epicardial artery stenoses, epicardial conductance vessels contribute only $10 \%-15 \%$ to total coronary vascular resistance, whereas regional blood flow and myocardial perfusion are determined by the tone of coronary resistance vessels. However, abnormal endothelial vasodilator function superimposed on even a mild stenosis might be an important mechanism contributing to myocardial ischaemia. ${ }^{1}$ Additionally, atherosclerotic wall thickening itself may, as a result of geometric magnification significantly exaggerate vasoconstrictor responses. ${ }^{24}$

Activation of the sympathetic nervous system, during activities such as exercise, mental stress, cold exposure, pain, cigarette smoking, and other stiumuli, is a well-known trigger of episodes of angina pectoris. ${ }^{1}$ The vasomotor response to sympathetic activation reflects the balance between endothelium-dependent dilatation mediated by increases in blood flow as well as by endothelial cell $\alpha_{2}$-adrenergic receptor stimulation ${ }^{7}$ and the direct $\alpha$-adrenergic receptor-mediated vasoconstrictor effects upon the vascular smooth muscle layer. It has been established that the paradoxical vasoconstriction in response to sympathetic activation observed in atherosclerotic epicardial arteries is related to dysfunction of the endotheliumdependent vasomotor regulation. ${ }^{25}$

In patients with hypercholesterolaemia, even angiographically normal coronary arteries fail to dilate in response to endotheliumdependent stimulation. ${ }^{13}$ Thus the alterations in endothelial vasodilator function induced by hypercholesterolaemia may implicate early changes in endothelial cell vasoactive function, which are important in the development of atherosclerosis in humans, rather than reflecting atherosclerosis per se. Even in the presence of atherosclerotic lesions, serum cholesterol fractions seem to have additional effects on endothelium-mediated vasoreactivity in human coronary conductance vessels. ${ }^{26}$ Raised LDL serum cholesterol concentrations are accompanied by a significant potentiation of atherosclerosis-associated impaired endothelial vasodilator function, ${ }^{26}$ whereas reduced HDL cholesterol concentrations intensify abnormal vasoconstriction in response to acetylcholine, ${ }^{26}$ and sympathetic stimulation. ${ }^{26}$ Thus high LDL and low HDL serum cholesterol concentrations may independently contribute to the development of myocardial ischaemia by further aggravating abnormal vasoconstriction of moderate epicardial artery stenosis in response to sympathetic activation. However, the presence of atherosclerotic lesions not only alters endothelial vasodilator function but also may affect vasoreactivity by increasing vascular stiffness and by thinning of the smooth muscle layer. ${ }^{27}$ Besides a loss of vasodilating properties that unbalances the vasomotor responses towards vasoconstriction, an exaggerated response to vasoconstrictor stimuli itself may also contribute to impaired endothelium-dependent vasodilator function of epicardial vessels in patients with hypercholesterolaemia. Threshold concentrations of endothelin-1, which do not have a direct vasoconstricting effect on the smooth muscle layer itself, sensitise the vascular smooth muscle to other vasoconstrictor stimuli such as catecholamines and serotonin. ${ }^{28}$ Indeed, there is preliminary evidence that endothelin-1, which is predominantly expressed by macrophages, is increased in the smooth muscle layer of atherosclerotic coronary artery segments of patients with hypercholesterolaemia. ${ }^{29}$

\section{CORONARY RESISTANCE VESSEIS}

Recent advances that allow the measurement of coronary blood flow during cardiac catheterisation have extended the observation of endothelial vasodilator dysfunction to the coronary microcirculation..$^{30}$ Coronary blood flow, which determines myocardial perfusion in the absence of epicardial stenoses, is predominantly regulated by microvessels $<200 \mu \mathrm{m}$ in diameter. Experiments with intracoronary administration of $\mathrm{L}-\mathrm{N}^{\mathrm{G}}$ monomethyl arginine, an arginine analogue blocking the NO-synthase, demonstrate that there is a tonic release of NO from the coronary microvasculature. ${ }^{31}$

Defective endothelium mediated vasodilatation of the coronary microcirculation has been demonstrated in patients without significant epicardial stenosis who had evidence of myocardial ischaemia detected by myocardial lactate production during papaverine administration $^{32}$ or by reduced blood flow increase during atrial pacing. ${ }^{31}$ In addition, impaired coronary blood flow responses to acetylcholine have been observed in patients without significant epicardial stenoses who had exerciseinduced myocardial ischaemia documented by thallium scintigraphy. ${ }^{33}$ These findings suggest that in the absence of epicardial artery stenoses, endothelial vasodilator dysfunction of the microcirculation is a major determinant for the development of myocardial ischaemia during increased metabolic demand.

Hypercholesterolaemia and advanced age have both been shown to impair selectively the endothelial vasodilator function of coronary resistance vessels in humans. ${ }^{14}$ There appears to be a close correlation between the extent of impaired endothelium-dependent vasodilator function of coronary resistance vessels and serum cholesterol concentrations, ${ }^{14}$ suggesting a dose-dependent phenomenon. In addition, impairment of resistance vessel vasodilator function in response to endothelium-dependent stimuli in hypercholesterolaemia is not confined to coronary microvessels, but also extends into the human forearm circulation, ${ }^{34}$ 
indicating a generalised endothelial vasodilator dysfunction associated with hypercholesterolaemia.

In some patients with evidence of atherosclerosis in their epicardial arteries, the vasodilator response of the microvasculature is impaired in response to cold exposure ${ }^{30}$ and atrial pacing. ${ }^{35}$ These results suggest a crucial role for the endothelium-dependent vasodilatation in coupling metabolic demand and coronary blood flow. Indeed Quyyumi and co-workers ${ }^{3136}$ convincingly demonstrated that metabolic vasodilatation in response to atrial pacing is largely mediated by NO. Most notably, in hypercholesterolaemia defective NO activity is in a large part responsible for the impaired endothelial vasodilator function. ${ }^{531}$ In both coronary and forearm resistance vessels, endothelium-mediated blood flow responses are closely correlated with basal NO activity, ${ }^{531}$ suggesting that the extent of endothelial vasodilator dysfunction reflects decreased NO activity. Thus defective NO activity associated with hypercholesterolaemia may not only contribute considerably to ischaemic manifestations of coronary artery disease in the absence of haemodynamically significant epicardial artery stenoses, but might also exacerbate ischaemic episodes in patients with advanced coronary artery disease.

\section{Therapeutic intervention}

The results of experimental studies have led to different strategies to improve endothelial vasodilator dysfunction in humans. Supplementation with L-arginine, the precursor of NO, has been shown in the short term to improve endothelial vasodilator function in animals $^{37}$ and in the human microcirculation ${ }^{38}$ without affecting endothelium-independent vascular function. Most importantly, chronic supplementation of L-arginine in hypercholesterolaemic animals reduces the extent of atherosclerotic lesion development without affecting serum cholesterol concentrations, suggesting a link between the L-arginine-NO pathway and atherogenesis. ${ }^{37}$ The mechanisms, by which $\mathrm{L}$ arginine improves endothelial function and reduces atherogenesis, remain to be determined. Normally, serum concentrations of $\mathrm{L}$ arginine are clearly sufficient to saturate the NO-synthase enzyme. ${ }^{39}$ Thus it seems paradoxical that supplementation of L-arginine increases the availability of NO in hypercholesterolaemia. ${ }^{39}$ However, a recent study indicates that oxidised LDL might have decreased the receptor-mediated availability of $\mathrm{L}$-arginine..$^{23}$ Moreover, L-glutamine in concentrations circulating in vivo might reduce $\mathrm{NO}$ availability selectively after receptor-mediated stimulation. ${ }^{40}$ Additionally, L-glutamine potentially inhibits the intracellular recycling of L-arginine from L-citrulline. Thus L-arginine supplementation in hypercholesterolaemia might overcome the inhibition of NO release by L-glutamine. However, it is not known whether hypercholesterolaemia is associated with alterations of the L-glutamine metabolism.

The most straightforward approach to improve endothelial function in hypercholes- terolaemia is to reduce cholesterol concentrations. Cholesterol lowering trials have demonstrated a substantial decrease of non-fatal myocardial infarction and total mortality. ${ }^{3}$ However, improvement of clinical outcome occurred despite only minimal regression of coronary atherosclerosis determined by angiography, ${ }^{3}$ suggesting that factors other than the reduction of atherosclerotic plaque size might be important for the benefit of cholesterol lowering therapy.

Improvement of endothelial function with cholesterol lowering therapy, which could be demonstrated in animals and in humans, ${ }^{41-43}$ probably contributes to the beneficial effects of cholesterol lowering therapy. In patients with angiographically normal coronary arteries, Leung and co-workers ${ }^{41}$ showed that a six month cholesterol lowering diet and cholestyramine therapy with a reduction in cholesterol concentration by $29 \%$, reversed the initial vasoconstrictor response to acetylcholine, indicating an improvement of endothelial function of the coronary conductance vessels. Egashira and co-workers ${ }^{42}$ extended this observation to the coronary microcirculation in patients with documented coronary artery disease: after six months of treatment with pravastatin, resulting in a cholesterol reduction of $31 \%$, coronary blood flow in response to acetylcholine increased by about $60 \%$. Recently, two prospective, placebo controlled, randomised studies demonstrated a significant reduction of the epicardial vasoconstrictor response to acetylcholine during six months' treatment with lovastatin and $\operatorname{diet}^{43}$ and a trend towards reduced vasoconstriction after one year of treatment with lovastatin and cholestyramine. ${ }^{44}$ In hypercholesterolemic patients, the addition of probucol to lipid lowering treatment with lovastatin further reduced acetylcholine-induced vasoconstriction compared with lipid lowering treatment with lovastatin and cholestyramine alone. This suggests that an antioxidant strategy may also improve endothelial dysfunction. ${ }^{44}$ Indeed, in cholesterol-fed animals, a reduction in cholesterol concentration was associated with normalisation of oxygen-derived free radical production. ${ }^{45}$

Improvement in endothelium-dependent regulation of the coronary artery tone may potentially contribute to a reduction in myocardial ischaemia and related symptoms in stable angina pectoris. Indeed, Gould et al found a significant improvement in myocardial perfusion, demonstrated by dipyridamole PET, during intensive lipid lowering. ${ }^{46}$ Thus not only the degree of stenosis, but also the functional status of the coronary wall is important in determining myocardial perfusion. In addition to functional improvement of myocardial perfusion, augmented endothelium-mediated vasodilator responses may precede structural regression of atherosclerosis ${ }^{47}$ and may serve as a marker for changes in the coronary vessel wall induced by lipid lowering treatment. The endothelium has the ability to regulate vascular growth, thrombus formation, and inflammation within the vessel wall, which 
are important processes in the course of coronary atherosclerosis and development of plaque rupture. Whether lipid lowering therapy also achieves a generalised improvement of these endothelial functions remains to be determined. However, resorption of cholesterol in plaques with large cholesterol pools ${ }^{46}$ as well as a reduction of inflammatory components associated with reduced oxidative stress caused by lipid lowering therapy is likely to diminish the propensity of atherosclerotic plaques to rupture. This would result in fewer clinical events such as unstable angina pectoris or myocardial infarction.

1 Meredith IT, Yeung AC, Weidinger FF, Anderson TJ, Uehata A, Ryan TJ, et al. Role of impaired endotheliumdependent vasodilation in ischemic manifestations of coronary artery disease. Circulation 1993;87:V-56-V-66.

2 Lopez JAG, Armstrong ML, Piegors DJ, Heistad DD. Effect of early and advanced atherosclerosis on vascular responses to serotonin, thromboxane $A_{2}$, and ADP.
Circulation 1989;79:698-705.

3 Levine GN, Keaney JF Jr, Vita JA. Cholesterol reduction in cardiovascular disease. Clinical benefits and possible mechanisms [comment]. N Engl f Med 1995;332:512-21.

4 Cohen RA, Zitnay KM, Haudenschild CC, Cunningham LD. Loss of selective endothelial cell vasoactive functions caused by hypercholesterolemia in pig coronary arteries. Circ Res 1988;63:903-10.

5 Casino PR, Kilcoyne CM, Quyyumi AA, Hoeg JM, Panza JA. The role of nitric oxide in endothelium-dependent vasodilation of hype

6 Cohen RA, Vanhoutte PM. Endothelium-dependent hyperpolarization-Beyond nitric oxide and cyclic GMP. Circulation 1995;92:3337-49.

7 Bassenge E, Busse R. Endothelial modulation of coronary tone. Prog Cardiovasc Dis 1988;349-80.

8 Palmer RMJ, Ashton DS, Moncada S. Vascular endothelial cells synthesize nitirc oxide from L-arginine. Nature 1988;333:664-6

9 Myers PR, Minor RL, Guerra R, Bates JN, Harrison DG. Vasorelaxant properties of the endothelium-derived relaxing factor more closely resembles S-nitrocysteine than nitric oxide. Nature 1990;345:161-3.

10 Vane JR, Anggard EE, Botting RM. Regulatory functions of the vascular endothelium. $N$ Engl $\mathcal{f}$ Med 1990; of the vascul.

11 Pohl U, Holtz J, Busse R, Bassenge E. Crucial role of endothelium in the vasodilator response to increased flow in vivo. Hypertension 1986;8:37-44.

12 Berliner JA, Navab M, Fogelman AM, Frank JS, Demer LL, Edwards PA, et al. Atherosclerosis: basic mechanisms. Oxidation, inflammation, and genetics. Circulation 1995;91:2488-96.

13 Zeiher AM, Drexler $H$, Wollschläger $H$, Just $H$. Modulation of coronary vasomotor tone in humans: progressive endothelial dysfunction with different early stages of

14 Zeiher AM, Drexler H, Saurbier B, Just H. Endotheliummediated coronary blood flow modulation in humans. mediated coronary blood flow modulation in humans. Effects of age, atherosclerosis, hypercholeste
hypertension. F Clin Invest 1993;92:652-62.

15 Minor RLJ, Myers PR, Guerra RJ, Bates JN, Harrison DG. Diet-induced atherosclerosis increases the release of nitrogen oxides from rabbit aorta. $\mathcal{F}$ Clin Invest 1990; 86:2109-16.

16 Ohara Y, Peterson TE, Harrison DG. Hypercholesterolemia increases endothelial superoxide anion production. $\mathcal{F}$ Clin Invest 1993;91:2546-51.

17 Mügge A, Elwell JH, Peterson TE, Harrison DG. Release of intact endothelium-derived relaxing factor depends on endothelial superoxide dismutase activity. Am $\mathcal{f}$ Physiol (Cell Physiol) 1991;260:C219-C225.

18 Zeiher AM, Fisslthaler B, Schray-Utz B, Busse R. Nitric oxide modulates the expression of monocyte chemoattractant protein 1 in cultured human endothelial cells. Circ Res 1995;76:980-6.

19 Matsuda Y, Hirata K, Inoue N, Suematsu M, Seinosuke $\mathbf{M}$, Kawashima S, et al. High density lipoprotein reverses inhibitory effect of oxidized low density lipoprotein on inhibitory effect of oxidized low density lipoprotein on 1993;72:1103-9.

20 Navab M, Imes SS, Hama SY, Hough GP, Ross LA, Bork $\mathrm{RW}$, et al. Monocyte transmigration induced by modification of low density lipoprotein in cocultures of human aortic wall cells is due to induction of monocyte chemotactic protein 1 synthesis and is abolished by high density lipoprotein. $\mathcal{F}$ Clin Invest 1991;88:2039-46.

21 Fleisher LN, Tall AR, Witte LD, Miller RW, Cannon PJ. Stimulation of arterial endothelial cell prostacyclin synthesis by high density lipoproteins. F Biol Chem 1982 257:6653-5

22 Shimokawa $\dot{H}$, Flavahan NA, Vanhoutte PM. Loss of endothelial pertussis toxin sensitive $G$ protein function in atherosclerotic porcine coronary arteries. Circulation 1991;83:652-60.

23 Tanner FC, Noll G, Boulanger CM, Lüscher TF. Oxidized low density lipoproteins inhibit relaxations of porcine coronary arteries. Role of scavenger receptor and endothelium-derived nitric oxide. Circulation 1991;83. 2012-20.

24 Schächinger V, Zeiher AM. Quantitative assessment of coronary vasoreactivity in humans in vivo: importance of baseline vasomotor tone in atherosclerosis. Circulation 1995;2087-94.

25 Zeiher AM, Drexler H, Wollschläger H, Saurbier B, Just $H$. Coronary vasomotion in response to sympathetic stimulation in humans: importance of the functional integrity of the endothelium. F Am Coll Cardiol 1989;14:1 181-90.

26 Zeiher AM, Schächinger V, Hohnloser SH, Saurbier B, Just $\mathrm{H}$. Coronary atherosclerotic wall thickening and vascular reactivity in humans. Elevated high-density lipoprotein levels ameliorate abnormal vasoconstriction in early atherosclerosis. Circulation 1994;89:2525-32.

27 Lee RT, Kamm RD. Vascular mechanics for the cardiologist. F Am Coll Cardiol 1994;23:1289-95.

28 Yang Z, Richard D, Von Segesser L, Bauer E, Stulz P, Turina M, et al. Threshold concentrations of endothelin1 potentiate contractions to norepinephrine and serotonin in human arteries: a new mechanism of vasospasm? Circulation 1990;82:188-95.

29 Zeiher AM, Thling C, Pistorius K, Goebel H, Schaefer HE. Hypercholesterolemia is associated with enhanced tissue Hypercholesterolemia is associated with enhanced tissue humans (abstract). Circulation 1994;90:I-576.

30 Zeiher AM, Drexler $H$, Wollschläger $H$, Just $H$. Endothelial dysfunction of the coronary microvasculature is associated with impaired coronary blood flow regula tion in patients with early atherosclerosis. Circulation 1991;84:1984-92.

31 Quyyumi AA, Dakak N, Andrews NP, Husain S, Arora S, Gilligan DM, et al. Nitric oxide activity in the human coronary circulation. F Clin Invest 1995;95:1747-55.

32 Egashira $\mathrm{K}$, Inou $\mathrm{T}$, Hirooka $\mathrm{Y}$, Yamada $\mathrm{A}$, Urabe $\mathrm{Y}$, Takeshita A. Evidence of impaired endothelium-dependent coronary vasodilation in patients with angina pectoris and normal coronary angiograms. $N$ Engl $f \mathrm{Med}$ 1993;328:1659-64.

33 Zeiher AM, Krause T, Schächinger V, Minners J, Moser E. Impaired endothelium-dependent vasodilation of coronary resistance vessels is associated with exercise-induced myocardial ischemia. Circulation 1995;91:2345-52.

34 Craeger MA, Cooke JP, Mendelsohn ME, Gallagher SJ, Coleman SM, Loscalzo J, et al. Impaired vasodilation of forearm resistance vessels in hypercholesterolemic humans. F Clin Invest 1990;86:228-34.

35 Nabel EG, Selwyn AP, Ganz P. Paradoxical narrowing of atherosclerotic coronary arteries induced by increases in heart rate. Circulation 1990;81:850-9.

36 Quyyumi AA, Dakak N, Andrews NP, Gilligan DM, Panza JA, Cannon RO, III. Contribution of nitric oxide to metabolic coronary vasodilation in the human heart. Circulation 1995;92:320-36.

37 Cooke JP, Singer AH, Tsao P, Zera P, Rowan RA, Billingham ME. Antiatherogenic effects of L-arginine in the hypercholesterolemic rabbit. $f$ Clin Invest 1992;90: the hyperch

38 Drexler $\mathrm{H}$, Zeiher AM, Meinzer $\mathrm{K}$, Just $\mathrm{H}$. Correction of endothelial dysfunction in coronary microcirculation of hypercholesterolemic patients by L-arginine. Lance 1991;338:1546-50.

39 Forstermann U, Closs EI, Pollock $M$, Nakane $M$, Schwar $\mathrm{P}$, Fath I, et al. Nitric oxide synthase isozymes. Characterization, purification, molecular cloning, an functions. Hypertension 1994;23:1121-31.

40 Arnal J-F, Münzel T, Venema RC, James NL, Bai CI, Mitch WE, et al. Interactions between L-arginine and L glutamine change endothelial NO production. An effect independent of NO synthase substrate availability. $f$ Cli Invest 1995;95:2565-72.

W/H, Iau CP, Wong CK. Beneficial effect of choles terol-lowering therapy on coronary endothelium-depen dent relaxation in hypercholesterolaemic patients. Lancet 1993;341:1496-1500

42 Egashira K, Hirooka Y, Kai H, Sugimachi M, Suzuki S, Inou $T$, et al. Reduction in serum cholesterol with pravastatin improves endothelium-dependent coronary vasomotion in patients with hypercholesterolemia. Circulation 1994;89:2519-24.

43 Treasure $\mathrm{CB}$, Klein $\mathrm{JL}$, Weintraub WS, Talley JD, Stillabower ME, Kosinski AS, et al. Beneficial effects of cholesterol-lowering therapy on the coronary endothelium in patients with coronary artery disease. $N$ Engl $f$ Med 1995;332:481-7.

44 Anderson TI, Meredith IT, Yeung AC, Frei B, Selwyn AP, Ganz $P$. The effect of cholesterol-lowering and antioxidant therapy on endothelium-dependent coronary vasodant therapy on endothelium-dependent coronary vas motion

45 Ohara Y, Peterson TE, Sayegh HS, Subramanian RR Wilcox JN, Harrison DG. Dietary correction of hypercholesterolemia in the rabbit normalizes endothelial superoxide anion production. Circulation 1995;92:898-903.

46 Gould KL, Martucci IP, Goldberg DI, Hess MJ, Eden RP, Latifi R, et al. Short-term cholesterol lowering decreases size and severity of perfusion abnormalities by positron emission tomography after dipyridamole in patients with coronary artery disease. A potential noninvasive marker of healing endothelium. Circulation 1994;89:1530-8.

47 Benzuly KH, Padgett RC, Kaul S, Piegors DJ, Armstrong ML, Heistad DD. Functional improvement precedes structural regression of atherosclerosis. Circulation 1994; 89:1810-18. 